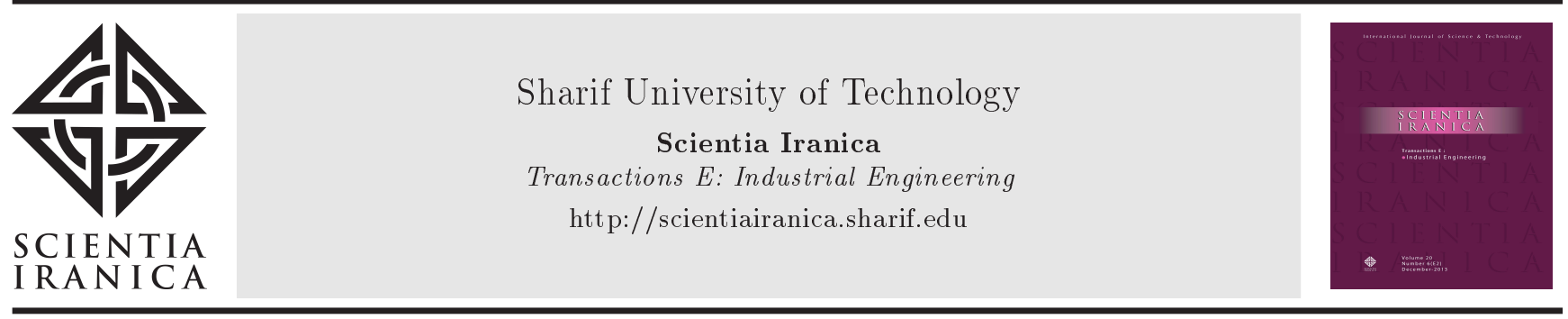

\title{
Master surgical scheduling problem with multiple criteria and robust estimation
}

\author{
R. Shafaei* and A. Mozdgir \\ Department of Industrial Engineering, K. N. Toosi University of Technology, Tehran 15875/4416, Iran. \\ Received 26 October 2016; received in revised form 15 May 2017; accepted 9 April 2018
}

\author{
KEYWORDS \\ Master surgical \\ scheduling; \\ Mathematical \\ programming; \\ Goal programming; \\ Robust estimation.
}

\begin{abstract}
In this research, the Master Surgical Scheduling (MSS) problem at the tactical level of hospital planning and scheduling is studied. Before constructing the MSS, a strategic level problem, i.e., Case Mix Planning Problem (CMPP), shall be solved to allocate the capacity of Operating Room (OR) to each surgical specialty. In order to make an effective coordination between CMPP and MSS, the results obtained from solving the CMPP are used as an input for the respective MSS. In the MSS, frequently performed elective surgeries are planned in a cyclic manner for a pre-defined planning period. As a part of the planning process, it is required to adjust downstream limited resources, such as Intensive Care Unit (ICU) and ward beds, with patient flow. In this study, a mathematical model is developed to construct an MSS. The proposed model is based on a lexicographic goal programming approach, which is aimed at minimizing the OR spare time while considering the results of the CMPP. In this paper, the data required to solve MSS are collected from a medium-sized Iranian hospital. Hence, a robust estimation method is applied to reduce the effect of outliers on the decision-making process. The results show the performance of the proposed method against the solution put in practice in the hospital.

(C) 2019 Sharif University of Technology. All rights reserved.
\end{abstract}

\section{Introduction}

Life expectancy is increasing in most countries and is rising, on average, by 3-4 months each year [OECD, 2013]. The ageing of society and the continuous growing demands for healthcare services make health care one of the most significant parts of public expenditure in many countries [1]. Regarding the healthcare cost, the most costly as well as beneficial parts of health systems are hospitals [2]. In addition, it is estimated that about $60 \%$ to $70 \%$ of the hospital admissions require OR [3]. As reported by "Healthcare Financial Management Association", OR results in an estimated $40 \%$ of the hospital revenue [4]. Therefore, hospital

*. Corresponding author. Tel.: +982184063375

E-mail address: Shafaei@rsct.ir (R. Shafaei)

doi: $10.24200 /$ sci.2018.20416 managers are normally concerned with handling surgeries through optimizing planning and scheduling of OR [5].

Elective surgery planning and scheduling is managed in three ways [6]: a) block scheduling, b) open scheduling, and c) modified block scheduling. Under the block scheduling system, a set of time blocks is assigned to specific surgical specialties in a cyclic schedule. In this way, the entire OR capacity is allocated to surgical specialties to obtain the ideal composition and volume of the patients in the hospital (the socalled CMP). Then, a cyclic timetable is constructed, determining which OR blocks are available for each surgical specialty (the so-called MSS problem). Finally, these blocks are designated to the patients and, then, are registered to the assigned time.

Under open scheduling strategy, namely "Any Workday" strategy [7], surgeons are allowed to choose their preferred surgery day. 
Finally, modified block scheduling intends to modify the scheduling strategy in two ways: a) keeping some blocks open, while others are booked; and b) replacing the unused blocks with the ones to be performed by other surgical specialties.

Adopting open scheduling strategy results in some problems in hospitals [5], whereas the block scheduling strategy is the most commonly used. The block scheduling smooths the variability in OR case volume by giving greater predictabilities to surgeons when booking their cases. Moreover, when evaluating case volume with regard to expectations, hospital targets, and surgeons, it creates more accountability [8]. This is why the block strategy is applied in Iran and in most hospitals.

In this study, we assume a block scheduling approach and propose a mathematical model to construct an optimal MSS on a one-week planning horizon. Specifically, our model is developed based on the real constraints and priorities of Iranian governmental hospitals. The proposed model produces a solution in line with the solution obtained from CMP. In addition, there are some special MSS problem objectives which shall be optimized. Therefore, a hierarchical goal programming approach is applied to consider these objectives.

Further, through this study, due to the existence of contamination in the collected data, a robust estimation approach was developed, which is not sensitive to the outliers. In statistical analysis, it is usually assumed that the data required for a problem follows a specific distribution. Thus, various classical methods, such as Maximum Likelihood Estimation (MLE), can be used to estimate distribution parameters. The required data for this study are collected from Shahid Madani Hospital Information System (HIS). Hence, the existence of outliers in the data gathered is indisputable. To overcome this problem, a robust estimation approach is developed to estimate the model' parameters.

Finally, using robust estimated parameters, the developed model is solved by applying GAMS software. Furthermore, sensitivity analysis of the results is conducted to study the impacts of variation of the parameters on the performance and find possibilities to improve the performance of the constructed MSS. Of note, our developed model can be applied to other hospitals. Indeed, our study is based on limitations and priorities that are common in Iranian hospitals, including the adoption of a block scheduling approach, consideration of OR, ward and ICU beds as critical resources, and incompatibility between surgeons and ORs. As a result, the developed model can be applied to a wide range of hospitals.

The remainder of the paper is structured as follows. Section 2 is concerned with the review of the related literature. Section 3 discusses problem description and mathematical programming model for the MSS. In Section 4, a robust estimation method is developed. Section 5 provides the results derived from solving model and their sensitivity analysis. Finally, Section 6 describes conclusions and potential areas for future studies.

\section{Literature review}

Various frameworks describe hospital operations management [5,8-10]. Hans et al. [11] proposed a generic scheme that comprised multiple managerial problems. They focused on four areas: medical planning, resource capacity planning, material planning, and financial planning. They classified hospital-planning issues into strategic, tactical, and operational decision levels. These levels of decisions are usually made in a hierarchical form, i.e., by considering the output of the upstream stage as the input for the subsequent downstream stage [12]. Regarding the resource capacity planning, the CMP problem is considered as one of the most important problem at a strategic level, while MSS problem and detail scheduling are considered as key problems at the tactical and operational levels. In the MSS problem, determining the assigning specialties to each OR in each day is the key to making operational decisions.

Review of researches revealed that many researchers studied the OR planning and scheduling problems. Recently, Samudra et al. [13] classified the recent OR planning and scheduling literature using patient type, various performance measures, decisions variables, OR supporting units, uncertainty, research methodology, and testing phase. They identified promising practices and trends and recognized common pitfalls when researching OR scheduling.

MSS is a core issue in hospitals' tactical planning and, hence, is considered as an important subject in optimizing the OR utilization. Review of researches on MSS reveals that this area has been rarely studied. However, the MSS has received much attention by the researchers in recent years. The most important aspect of this subject that has been considered in the related literature on MSS is levelling the postsurgery units [12,14-16]. In addition, some researchers have considered the uncertainty of the parameters in MSS problem. This includes uncertainty on Operating Time (OT) and Length Of Stay (LOS) in post-surgery units $[12,15,17-19]$. Furthermore, various performance measures have been used to evaluate the performance of MSS solutions. One of the commonly applied objectives is financial goals. For instance, in some researches, authors have examined how proper MSS construction contributes to the improvement of financial goals [18-20]. Van Oostrum et al. [15], Agnetis et 
al. [21], and Cappanera et al. [22] also considered utilization as a performance criterion. In addition, other performance measures, such as levelling [12,14,15,22], throughput [23], and preferences [14], are applied to the researches. However, some studies consider a higher number of performance criteria rather than merely one criterion $[24,25]$. An overview of studies related to the MSS problem is presented as follows.

Banditori et al. [23] addressed a combined optimization-simulation approach to the MSS problem. They presented a mixed integer programming model which produced a solution that indicates, for each day of the month and for each time slot of the day, the assigned surgery specialties and the number of cases to treatment. Their aim was to maximize the patient throughput to take into account the cases' due dates and to allow for control of the waiting list. Then, they illustrated the results of a simulation study through which they tested robustness of the model solution against the randomness of surgery duration and the LOS. Beliën et al. [14] presented a decision support system for cyclic MSS. They took into account three objectives when building the MSS: levelling the resulting bed occupancy at the hospitalization units, allocating a particular OR to one specialty of surgeons with the same specialty as much as possible, and building the MSS as simple and repetitive as possible, with few changes from week to week. They developed a mixed integer programming model by associating the solution of multi-objective linear with quadratic optimization problems and used a simulated annealing metaheuristics.

Agnetis et al. [21] investigated long-term policies to determine the MSS throughout the year. They analyzed the trade-off between the quality of the service offered to the patients (favored by an MSS) and organizational simplicity, favored by an MSS that dynamically adapts to the current state of waiting lists or does not change completely every week. They applied Integer Linear Programming (ILP) formulations and analyzed the scalability of the approach in larger hospitals. Results of the simulations revealed that introducing a limited degree of variability in MSS could largely affect resource efficiency and due date performance. Cappanera et al. [22] compared three different scheduling policies in the MSS problem with respect to three performance criteria: efficiency, balancing, and robustness. They developed a mixedinteger programming model and compared three objective functions. All of the policies maximized the number of the scheduled surgeries and balanced the utilization of beds, OR and post-surgical units. They also employed a discrete event simulation model to assess the robustness of the MSS model solution. The results of the study revealed that these policies do not lead to obtaining superior performance in terms of concurrently achieved efficiency, balancing, and robustness. Holte and Mannino [26] modeled uncertain and cyclic allocation problem as robust scheduling problems. They developed a row and column generation algorithm to solve the model, and showed that it corresponded to the implementer algorithm for robust optimization. Visintin et al. [27] presented a novel mixed integer programming model to support MSS construction. They also applied the model to investigate the performance of the proposed model in terms of flexible management of the three critical resources: surgical teams, surgical and OR units. The results indicated that it is required to present flexibility in terms of surgical teams and OR to maximize the number of surgeries scheduled. Rowse et al. [28] developed a set partitioning formulation in order to assign surgical specialties to OR, aiming to decrease the number of cancelled or referral surgeries. They also leveled the demand for beds throughout the week. Furthermore, they applied a novel extension model to incorporate limitations on the demand for post-surgery beds.

Van Oostrum et al. [15] applied a mathematical programming model to construct an MSS considering probabilistic constraints. They proposed a column generation approach to maximize OR utilization and levels of the requirements for post-surgery beds concurrently.

Fügener [29] also discussed an MSS approach that maximized hospital revenues while considering the effect on the downstream resources beds. He applied an integer programming model to find the optimal allocation of how many and what OR blocks are to be assigned to each surgical specialty, which are strategic and tactical planning problems, respectively.

Van Oostrum et al. [30] discussed the advantages and disadvantages of MSS and compared them with the results obtained using centralized and decentralized planning approaches. Moreover, they addressed various implementation issues of the MSS and discussed its suitability for application in hospitals in different circumstances.

Visintin et al. [31] reported the results of an action research project which aimed to develop and implement an OR scheduler. Their study offered insights into the features that make MSS optimization model effective and easy to implement. They stated that outliers in OT and LOS need to be managed accurately and suggested the adjusted boxplot method to filter both OT and LOS.

Recently, Cappanera et al. [24] proposed a mixed integer goal programming model to support the MSS process. In order to comply with the process stakeholders, their objective comprised four criteria: (1) considering the patients' priorities, (2) balancing the utilization of the OR, (3) balancing the utilization of the post-surgical units, and (4) maximizing the number 
of scheduled surgeries. The authors tested the model on real data collected from a leading Italian hospital. Moreover, Cappanera et al. [25] proposed a mixed integer multi-objective model to construct an MSS with the objectives of obtaining: (1) patients' desired due date fulfillment rate, (2) OR utilization, (3) bed utilization, and (4) the number of scheduled surgeries. To address the described multi-objective problem, they used a goal programming approach and showed how the exploration of the weight space could be more efficient if it was informed by a correlation analysis.

Based on the literature reviewed above and according to the best of the author's knowledge, researchers have not yet studied neither performance measures of governmental Iranian hospital, nor down weighting outlier data obtained from the HIS. Thus, this study focuses on constructing an MSS while considering real-world conditions of Iranian hospitals.

\section{Problem definition and mathematical formulation of the problem}

MSS is a core subject in a mid-term hospital management. In MSS, elective surgical operations are planned in a given planning cyclic manner. In constructing the MSS, surgical operations of a certain type are scheduled. Generally, there are two categories of operations: elective and non-elective operations.

Following the nature of the introduced categories described above, the MSS is concerned only with the elective operations. However, in developing MSS, the capacity for the non-elective operations shall be reserved. In the process of constructing the MSS, there are two stages to be performed consecutively. First, hospital managers define MSS cycle length and determine how the OR capacity is divided over elective and non-elective patients. Then, each surgical specialty is assigned to the blocks in the MSS. Note that emergency surgeries are scheduled during the execution of the elective schedule at a short-term decision level. In this study, a mathematical model is developed to construct the MSS for elective surgeries while using the results obtained from solving CMPP as input. Moreover, based on the hospital requirements, a part of the capacity of OR is reserved for emergency surgeries. In addition, in case the demand for emergency operations exceeds the capacity planned, the capacity of the elective operations is reduced, and corresponding elective operations are postponed accordingly.

Herein, an ILP model for determining block assignment to the surgical specialties is described. Table 1 shows sets, variables, and parameters required for modeling of the MSS problem.

Parameter $\psi_{d^{\prime}}$ igc is defined to calculate the average requirement for the number of beds of ward $c$ on day $\tau$ for an operation of patient sex group $g$ of surgical specialty $i$, if this surgery is scheduled on day $d$. The procedure to calculate this parameter is described in Appendix A.

\subsection{The constraints of the MSS problem}

In this study, the constraints and objectives of the model are obtained through targeted interviews by the medical staffs. The considered constraints consist of OR block capacity, number of parallel blocks assigned to surgical specialties, ward and ICU beds capacities, and lower and upper limits on the OR block time allocated to each surgical specialty.

According to the size and equipped facilities of each OR, some of OR blocks cannot be assigned to specific surgical specialties. Likewise, certain operations of surgical specialties can only be performed in a restricted set of OR blocks. On the other hand, each OR block can only be assigned to one surgical specialty in each day. Eqs. (1) and (2) guarantee the possibility of assigning OR blocks to the designated surgical specialties:

$$
\begin{aligned}
& \sum_{i} x_{i b r d} \leq 1 \quad \forall b, r, d, \\
& x_{i b r d} \leq R_{i r} \quad \forall i, b, r, d .
\end{aligned}
$$

Typically, the number of doctors, probability of emergency arrival, and resource restrictions limit the number of allocated blocks to the surgical specialties simultaneously. Constraint (3) represents the corresponding constraints:

$$
\sum_{r} x_{i b r d} \leq P I_{i} \quad \forall i, b, d
$$

OR planning and scheduling affect downstream resources throughout the hospital. Moreover, the capacity of subsequent departments, such as wards and ICU, shall be considered as important capacity constraints. Otherwise, improving the OR planning and scheduling solely may decrease the efficiency of those related resources and may cause local optimum planning and scheduling. Therefore, capacity of wards and ICU is considered as an important constraint in the MSS problem. These constraints are given in Eq. (4).

$$
\begin{aligned}
& \sum_{i} \sum_{g} \sum_{b} \sum_{r} \psi_{d \tau i g c} \times x_{i b r d} \times A_{i g} \times \frac{O_{b r d}}{T_{i}} \leq w_{c} \\
& \forall d, \tau, c .
\end{aligned}
$$

Since the model developed in this research is based on the data collected from Shahid Madani hospital and given that this hospital is a referral hospital, it is assumed that, in each surgical specialty, the minimum 
Table 1. The proposed model sets, variables, and parameters.

\begin{tabular}{|c|c|}
\hline & Definition \\
\hline \multicolumn{2}{|l|}{ Sets: } \\
\hline I & Set of surgical specialties, indexed by $i$ \\
\hline $\mathrm{R}$ & Set of OR, indexed by $r$ \\
\hline $\mathrm{C}$ & Set of wards, indexed by $c$ \\
\hline G & Set of patients' sex groups (male, female, and pediatrics), indexed by $g$ \\
\hline $\mathrm{B}$ & Set of OR blocks (morning and afternoon), indexed by $b$ \\
\hline $\mathrm{T}$ & Set of weekdays, indexed by $\tau$, from Saturday $(\tau=1)$ to Friday $(\tau=7)$ \\
\hline $\mathrm{D}$ & $\begin{array}{l}\text { Set of weekdays in which elective surgeries can be performed by special surgeons, } \\
\text { indexed by } d \text {, from Saturday }(d=1) \text { to Wednesday }(d=5) \text { (working day in Iran) }\end{array}$ \\
\hline \multicolumn{2}{|c|}{ Variables: } \\
\hline$x_{i b r d}$ & $\begin{array}{l}\text { If surgical specialty } i \text { is assigned to OR } r \text { on day } d \text { in a block of } \\
\text { type } b \text {; it is equal to } 1 \text {; otherwise, } 0\end{array}$ \\
\hline$E C_{i}$ & Total OR idle time in the assigned blocks of surgical specialty $i$ \\
\hline \multicolumn{2}{|c|}{ Parameters: } \\
\hline$O_{b r d}$ & Available capacity of OR $r$ on day $d$ in block $b$ \\
\hline$P I_{i}$ & Maximum number of parallel blocks assigned to surgical specialty $i$, \\
\hline$R_{i r}$ & If OR $r$ is appropriate for the surgical specialty $i$, it is equal to 1 ; otherwise, 0 \\
\hline$P N_{i}$ & Assigned priority of surgical specialty $i$ \\
\hline$D_{i}$ & Average demand of elective patients of surgical specialty $i$ in a week \\
\hline$w_{c}$ & Ward $c$ beds capacity \\
\hline$\psi_{d \tau i g c}$ & $\begin{array}{l}\text { Average requirements for ward } c \text { bed on day } \tau \text { for an operation of patient sex } \\
\text { group } g \text { of surgical specialty } i \text {, if this procedure is scheduled on day } d \text {. }\end{array}$ \\
\hline$s t w_{i}$ & Average LOS of surgical specialty $i$ patients in the ward \\
\hline$s t I_{i}$ & Average LOS of surgical specialty $i$ patients in the ICU \\
\hline$P_{i}$ & Average duration of surgery of surgical specialty $i$ \\
\hline$A_{i g}$ & Rate of patients' sex group $g$ in surgical specialty $i$ \\
\hline$T$ & Cycle length \\
\hline$C M P_{i}$ & Allocated time to surgical specialty $i$ in the CMPP \\
\hline
\end{tabular}

number of OR blocks shall be carried out. On the other hand, in case the capacity of a specific specialty is decided to be reduced, such a change shall be gradual in order to deal with the demand. Hospital policy is based on gradual reduction of capacity for the surgical specialties whose capacity should be reduced. Finally, it is assumed that the time of OR blocks allocated to surgical specialty $i$ shall not exceed its maximum time required, i.e., the demand of surgical specialty $i$. Constrains (5) and (6) determine lower and upper limits of the OR block time allocated to each surgical specialty throughout the planning horizon, respectively.

$$
\sum_{r} \sum_{b} \sum_{d} x_{i b r d} \times O_{b r d} \geq\left(1-\alpha_{i}\right) \times \operatorname{Cap}_{i}
$$

$$
\sum_{r} \sum_{b} \sum_{d} \frac{x_{i b r d} \times O_{b r d}}{T_{i}} \leq D_{i} \quad \forall i .
$$

Because OR blocks are totally assigned to surgical specialties, it is possible that some OR blocks have idle time. In this case, Eqs. (5) and (6) may be incompatible. Therefore, Eq. (7) shall be amended as follows:

$$
\sum_{r} \sum_{b} \sum_{d} x_{i b r d} \times O_{b r d} \leq\left(D_{i} \times T_{i}\right)+E C_{i},
$$

In Eq. (7), $E C_{i}$ shows the amount of excess capacity assigned to surgical specialty $i$.

\subsection{Objective function}

Normally, an MSS is constructed based on the hospital CMP, which is a strategic level decision. Therefore, 
because the decisions of the lower levels should be made in line with the decisions of the higher levels in any decision problem, the results of an optimum MSS shall support the CMP the greatest extent possible. However, there are some sub-goals in the MSS problem that should be optimized, i.e., total amount of $E C_{i}$. Therefore, a lexicographic goal programming approach is developed to consider these criteria. Lexicographic goal programming, sometimes called 'pre-emptive' goal programming in the literature, is used when the decision-maker has natural ordering of deviations from goals as their preferences, or it is not acceptable to compare goals directly. In this case, there is a number of priority levels, each of which contains a number of unwanted deviations to be minimized. Then, a goal programming problem can be solved as a series of linear programs. In this study, the first priority is the closeness between total time block assigned to surgical specialties resulting from MSS and the time assigned to surgical specialties resulting from CMP, while the second priority is to minimize the sum of the spare capacity, which is assigned to the surgical specialties in MSS.

The term $C M P_{i}-\sum_{r} \sum_{b} \sum_{d} x_{i b r d} \times O_{b r d}$ shows the difference between the time allocated to surgical specialty $i$ by CMP and MSS. If the difference is positive, it means that the capacity allocated to surgical specialty $i$ in the MSS is less than the pre-allocated capacity allocated by the CMP. In this case, the goal is to $\operatorname{minimize} \sum_{i} \max \left(0, x_{i}-\sum_{r} \sum_{b} \sum_{d} x_{i b r d} \times O_{b r d}\right)$. On the other hand, elective operations of various surgical specialties differ in importance. To indicate the relative importance of elective operations of surgical specialty $i$, priority factor $P N_{i}$ is defined. To ensure that the objective function is not influenced by the amount of the time allocated to surgical specialties in the CMP phase, but only by the rate of decreased time and their relative importance, $C M P_{i}-\sum_{r} \sum_{b} \sum_{d} x_{i b r d} \times O_{b r d}$ is normalized for any surgical specialty. The normalization factor is the time allocated to each surgical specialty in the CMP phase: $C M P_{i}$. This yields the normative sum of the maximum difference between allocated capacities in CMP and MSS of all surgical specialties:

$$
\min \sum_{i} \max \left(0, P N_{i}\left(\frac{x_{i}-\sum_{r} \sum_{b} \sum_{d} x_{i b r d} \times O_{b r d}}{x_{i}}\right)\right) \text {. }
$$

If the term $C M P_{i}-\sum_{r} \sum_{b} \sum_{d} x_{i b r d} \times O_{b r d}$ is negative, then the capacity allocated to surgical specialty $i$ in the MSS is greater than the pre-allocated capacity allocated by the CMP. In this case, if this allocated capacity is greater than the surgical specialty demand, there is a spare time or underutilization for the blocks, which are assigned to surgical specialty $i$. Therefore, the corresponding goal is to minimize $\sum_{i} E C_{i}$ :

$$
\min \sum_{i} E C_{i}
$$

In Eq. (8), priority factor $P N_{i}$ denotes the relative importance of elective operations of surgical specialty $i$. This factor is calculated based on "assigned priority". To calculate this priority based on the hospital policy, three criteria shall be taken into account. These criteria are: 1) patients' demands concerning surgical specialty, 2) possibility of referring surgical specialty patients to other hospitals, and 3 ) the number of emergency surgeries for each surgical specialty. Shahid Madani is a governmental referral hospital. Hence, patients' demands concerning surgical specialty can be one of the most important parameters to be considered when "assigned priority" is calculated. In addition, since the aim of a governmental hospital is to cover the most required patients as many as possible, the patients who have less chance for admission in the other hospitals are given more priority. On the other hand, since the hospital managers intend to cover all emergency surgeries, the number of surgeons for each surgical specialty is affected by the rate of the respective emergency surgeries inherently. Therefore, hospital managers tend to give more capacity to those surgical specialties, with a high rate of emergency operations. Table 2 shows the effective parameters related to the "assigned priority" according to the data collected in the period of March 20, 2014 to July 21, 2015.

Since the "assigned priority" is calculated based on different criteria, the Technique for Order of Preference by Similarity to Ideal Solution (TOPSIS) is applied to this research. TOPSIS [32] represents a classical multi-criteria decision-making method. Hwang

Table 2. Effective parameters related to the "assigned priority".

\begin{tabular}{cccc}
\hline $\begin{array}{c}\text { Surgical } \\
\text { specialty }\end{array}$ & $\begin{array}{c}\text { Number of } \\
\text { elective } \\
\text { demand }\end{array}$ & $\begin{array}{c}\text { Number of } \\
\text { alternative } \\
\text { hospital }\end{array}$ & $\begin{array}{c}\text { Rate of } \\
\text { emergency } \\
\text { surgery }\end{array}$ \\
\hline CNS & 400 & 5 & 0.0306 \\
ENT & 271 & 5 & 0.0089 \\
Orology & 353 & 7 & 0.0077 \\
Orthopedic & 3398 & 7 & 0.6211 \\
Eye & 813 & 6 & 0.0032 \\
Hand & 748 & 1 & 0.0659 \\
Burn & 114 & 0 & 0.0023 \\
Vascular & 104 & 3 & 0.0187 \\
General & 885 & 9 & 0.2387 \\
Maxillofacial & 104 & 0 & 0.0027 \\
\hline
\end{tabular}


and Yoon [33] originally developed it. This technique ranks alternatives according to their shortest geometric distance from the Positive Ideal Solution (PIS) and the longest geometric distance from the Negative Ideal Solution (NIS). The PIS is defined using the best rate of the values of the alternatives for each individual criterion; conversely, the NIS represents the worst values of the rate of alternatives [33]. The ranking of the alternatives is based on the relative similarity to the ideal solution. TOPSIS process is described in Appendix B.

\section{Robust estimation}

In statistical analysis, it is usually assumed that the data are distributed according to a specified distribution. Therefore, the parameters of interest are usually estimated using classical methods such as MLE or MME. In this study, the parameters of the model are estimated based on the data collected from Shahid Madani HIS. Like other sample data, hospital data may include outliers. Thus, estimators, called robust estimators, are used to estimate the parameters, which are insensitive to the contamination. The details of MLE and robust estimators are described as follows.

\subsection{Maximum likelihood estimation of the parameters}

The distributions of the random variables in the problem studied are discrete. Let $Y$ denote the random variable with possible values 1 to $m$ with the probabilities of occurrence $\theta_{1}, \theta_{2}, \ldots, \theta_{m}$, respectively. Thus, the probability mass function of $Y$ is defined as follows:

\begin{tabular}{c|c|c|c|c}
$y$ & 1 & 2 & $\ldots$ & $m$ \\
\hline$P(Y=y)$ & $\theta_{1}$ & $\theta_{2}$ & $\ldots$ & $\theta_{m}$
\end{tabular} follows:

The probability mass function may be defined as

$$
P(Y=y)=f_{Y}(y)=\theta_{1}^{I(y=1)} \theta_{2}^{I(y=2)} \ldots \theta_{m}^{I(y=m)},
$$

where $I($.$) is the indicator function.$

Suppose that $Y_{1}, \ldots, Y_{n}$ is a random sample of size $n$ with a probability mass function of $f_{Y}(y)$. Thus, the likelihood function is defined as follows:

$$
L\left(\theta_{1}, \theta_{2}, \ldots, \theta_{m}\right)=\theta_{1}^{\#\left(y_{i}=1\right)} \theta_{2}^{\#\left(y_{i}=2\right)} \ldots \theta_{m}^{\#\left(y_{i}=m\right)},
$$

where \# $(A)$ denotes the number of elements of set $\mathrm{A}$.

By defining sample proportion $f_{i}$, we have:

$$
f_{i}=\frac{1}{n} \sum_{j=1}^{n} I\left(y_{j}=i\right) \quad i=1,2, \ldots, m .
$$

Thus:

$$
L\left(\theta_{1}, \theta_{2}, \ldots, \theta_{m}\right)=\theta_{1}^{n f_{1}} \theta_{2}^{n f_{2}} \ldots \theta_{m}^{n f_{m}} .
$$

By defining $L^{*}=L^{\frac{1}{n}}$ and $l^{*}=\log L^{*}$, we have:

$$
\begin{aligned}
L^{*}\left(\theta_{1}, \theta_{2}, \ldots, \theta_{m}\right)= & \theta_{1}^{f_{1}} \theta_{2}^{f_{2}} \ldots \theta_{m}^{f_{m}}, \\
l^{*}\left(\theta_{1}, \theta_{2}, \ldots, \theta_{m}\right)= & f_{1} \log \theta_{1}+f_{2} \log \theta_{2} \\
& +\ldots+f_{m} \log \theta_{m}, \\
l^{*}\left(\theta_{1}, \theta_{2}, \ldots, \theta_{m}\right)= & \sum_{i=1}^{m} f_{i} \log \theta_{i}, \\
\mathrm{s.t.:} \sum_{i=1}^{m} \theta_{i}=1 & \\
l^{*}\left(\theta_{1}, \theta_{2}, \ldots, \theta_{m}\right)= & \sum_{i=1}^{m} \frac{f_{i}}{\theta_{i}} \times \theta_{i} \log \left(\frac{\theta_{i}}{f_{i}} \times f_{i}\right) \\
l^{*}=-\sum_{i=1}^{m} \rho\left(\frac{f_{i}}{\theta_{i}}\right) \theta_{i} & +\sum_{i=1}^{m} \frac{f_{i}}{\theta_{i}} \times \theta_{i}\left[\log \left(\frac{\theta_{i}}{f_{i}}\right)+\log f_{i}\right] \\
= & \sum_{i=1}^{m} \frac{f_{i}}{\theta_{i}} \times \theta_{i}\left[\log \left(\frac{\theta_{i}}{f_{i}}\right)+\log f_{i}\right] \\
& \sum_{i=1}^{m}-\frac{f_{i}}{\theta_{i}} \times \theta_{i}\left[\log \left(\frac{f_{i}}{\theta_{i}}\right)\right]
\end{aligned}
$$

where $A$ is the last term free of $\theta_{1}, \ldots, \theta_{m}$ and $\rho(x)=$ $x \log x$. Therefore, in order to estimate $\theta_{1}, \ldots, \theta_{m}$, the value of $A-l^{*}$ shall be minimized. In order to estimate the values of $\theta_{1}, \ldots, \theta_{m}$, the following mathematical programming model needs to be solved:

$$
\begin{aligned}
& \min Q=\sum_{i=1}^{m} \rho\left(\frac{f_{i}}{\theta_{i}}\right) \theta_{i}, \\
& \text { s.t.: } \\
& \sum_{i=1}^{m} \theta_{i}=1 \quad 0 \leq \theta_{i} \quad i=1, \ldots, m .
\end{aligned}
$$

The Lagrange function of the above-defined mathematical programming model can be defined as follows:

$$
Z=\sum_{i=1}^{m} \theta_{i} \rho\left(\frac{f_{i}}{\theta_{i}}\right)+\lambda\left(\sum_{i=1}^{m} \theta_{i}-1\right),
$$

which is equivalent to: 


$$
\begin{aligned}
Z & =\sum_{i=1}^{m} \theta_{i} \frac{f_{i}}{\theta_{i}} \log \left(\frac{f_{i}}{\theta_{i}}\right)+\lambda\left(\sum_{i=1}^{m} \theta_{i}-1\right) \\
& =\sum_{i=1}^{m} f_{i} \log \left(\frac{f_{i}}{\theta_{i}}\right)+\lambda\left(\sum_{i=1}^{m} \theta_{i}-1\right) .
\end{aligned}
$$

In order to solve the addressed mathematical programing, the following gradient is calculated:

$$
\frac{\partial Z}{\partial \theta}=0 \Rightarrow f_{j}=\lambda \theta_{j}
$$

which can also be written as follows:

$$
\sum_{j=1}^{m} f_{j}=\lambda \sum_{j=1}^{m} \theta_{j}
$$

Since $\sum_{j=1}^{m} f_{j}=\sum_{j=1}^{m} \theta_{j}=1$, according to Eq. (23), the value of $\lambda$ and the MLE for parameter $\theta$ are defined as follows:

$$
\begin{aligned}
& \lambda=1, \\
& \hat{\theta}_{i}=f_{i} .
\end{aligned}
$$

\subsection{Robust estimation of the values of the problem parameters}

In statistics, an observation, which is distant from other observations, is referred to as an outlier [34,35]. Robust estimators can be used to cope with outliers [36].

Like other sample data, hospital data may include outliers. Freitas et al. [37] studied factors that influence hospital outliers for longer-stay patients. They found a proportion of $3.9 \%$ high LOS outliers accounting for $19.2 \%$ of the total inpatient days. A study on a couple of public Spanish hospitals revealed that $4.8 \%$ of the total patient discharges represent $15.4 \%$ of total LOS and $17.9 \%$ of total hospital costs [38]. In addition, Pirson et al. [39] studied the cost outliers in a Belgian hospital. The results showed that $6.3 \%$ of the high resources use outliers, and $1.1 \%$ of low resources use outliers. In this study, on CMPP in Shahid Madani hospital, the collected data can include outliers. Therefore, using methods to tackle this problem is necessary. However, there is no absolute mathematical definition to detect an outlier [40,41].

Traditionally, to remove the outlier, statisticians would manually screen data and check the source of the data. However, in modern techniques, according to the size of the datasets and large numbers of the experimental units, manual screening for outliers is often impractical. Robust methods provide automatic ways of detecting, down-weighting, and flagging outliers, which can be replaced with manual screening [36]. Robust estimators are statistical estimators with good performance in estimating the parameters for a wide range of probability distributions. One of the most important motivations of using robust estimators is to produce statistical methods that are not seriously affected by the outliers.

In this study, the derived data are collected from Shahid Madani HIS. Thus, a robust estimator is used which is insensitive to the contamination. The robust estimators of discrete distribution parameters must be absolutely used in this study. In 2001, Ruckstuhl and Welsh [42] discussed that the data discreteness and the limited parameter space led standard robust theory to remarkable results. They developed a new class of estimators for the binomial distribution parameter, named 'E-estimators'. Due to the discreteness nature of distribution of the data in this work, this study was inspired by the methods developed by Ruckstuhl and Welsh [42] in estimating the parameters robustly.

As is shown in Eq. (19), the likelihood function of random sample is defined as follows:

$$
Z=\sum_{i=1}^{m} \theta_{i} \rho\left(\frac{f_{i}}{\theta_{i}}\right)
$$

where:

$$
\rho(x)=x \log x .
$$

In the absence of contamination, $\rho(x)$ is equal to $x \log x$. However, it will not be equal to $x \log x$ if there is contamination in the data. Hence, this problem can be defined as an optimization problem in which $\rho(x)$ is a function with special properties that is not necessarily equal to $x \log x$.

$$
\begin{aligned}
& \operatorname{Min} Z=\sum_{i=1}^{m} \theta_{i} \rho\left(\frac{f_{i}}{\theta_{i}}\right), \\
& \text { s.t.: } \\
& \sum_{i=1}^{m} \theta_{i}=1, \\
& \theta_{i} \geq 0 \quad i=1,2, \ldots, m,
\end{aligned}
$$

which is the same as writing:

$$
\theta_{i}-s_{i}^{2}=0 \quad \forall i=1,2, \ldots, m .
$$

The Lagrange function of the above problem can be defined as follows:

$$
Z=\sum_{i=1}^{m} \theta_{i} \rho\left(\frac{f_{i}}{\theta_{i}}\right)-\lambda\left(\sum_{i=1}^{m} \theta_{i}-1\right)-\sum_{i=1}^{m} \mu_{i}\left(\theta_{i}-s_{i}^{2}\right)
$$

where all the variables are free. Also, $\Theta$ is used as the decision variable vector; thus: 
$\Theta=\left(\theta_{1}, \theta_{2}, \ldots, \theta_{m}, \lambda, \mu_{1}, \mu_{2}, \ldots, \mu_{m}, s_{1}, s_{2}, \ldots, s_{m}\right)^{\prime}$.

To solve the optimization problem, Eq. (28), the gradient must be calculated as follows:

$$
F=\frac{\partial Z}{\partial \Theta}
$$

If:

$$
\rho(x)=\Psi \quad \text { and } \quad \Psi(x)=\xi(x),
$$

then:

$$
\begin{aligned}
\frac{\partial Z}{\partial \theta_{j}} & =\rho\left(\frac{f_{j}}{\theta_{j}}\right)-\theta_{j} \times \frac{f_{j}}{\theta_{j}^{2}} \Psi\left(\frac{f_{j}}{\theta_{j}}\right)-\lambda-\mu_{j}, \\
\frac{\partial Z}{\partial \theta_{j}} & =\rho\left(\frac{f_{j}}{\theta_{j}}\right)-\frac{f_{j}}{\theta_{j}} \Psi\left(\frac{f_{j}}{\theta_{j}}\right)-\lambda-\mu_{j}, \\
\forall j & =1,2, \ldots, m, \\
\frac{\partial Z}{\partial \lambda} & =-\left(\sum_{i=1}^{m} \theta_{i}-1\right) \\
\frac{\partial Z}{\partial \mu_{j}} & =-\theta_{j}+s_{j}^{2} \quad \forall j=1,2, \ldots, m \\
\frac{\partial Z}{\partial s_{j}} & =2 \mu_{j} s_{j} \quad \forall j=1,2, \ldots, m,
\end{aligned}
$$

and system of Eq. (33) is shown in Box I.

In order to solve the above optimization problem, $F(\Theta)=0$ shall be solved. According to the nonlinearity of some equations in the system of Eq. (33), Newton-Rophson method is applied. Thus:

$$
\Theta^{N}=\Theta^{O}-J_{\theta_{O}}^{-1} F\left(\Theta^{O}\right)
$$

where $\Theta^{N}$ is defined as an estimation for new value of the root, while $\Theta^{O}$ and $J$ represent the current value of the root and Jacobian matrix of system of equations, respectively. To form the Jacobian matrix, the gradient of $F$ must be calculated for each variable. This gradient for the first $m$ equations is defined as follows:

$$
\begin{aligned}
\frac{\partial^{2} Z}{\partial \theta_{j}{ }^{2}}= & -\frac{f_{j}}{\theta_{j}{ }^{2}} \Psi\left(\frac{f_{j}}{\theta_{j}}\right)-\left[-\frac{f_{j}}{\theta_{j}{ }^{2}} \Psi\left(\frac{f_{j}}{\theta_{j}}\right)\right. \\
& \left.-\frac{f_{j}}{\theta_{j}} \frac{f_{j}}{\theta_{j}{ }^{2}} \xi\left(\frac{f_{j}}{\theta_{j}}\right)\right] \quad \forall j=1,2, \ldots, m, \\
\frac{\partial^{2} Z}{\partial \theta_{j}{ }^{2}}= & \frac{f_{j}{ }^{2}}{\theta_{j}{ }^{3}} \xi\left(\frac{f_{j}}{\theta_{j}}\right) \quad \forall j=1,2, \ldots, m, \\
\frac{\partial^{2} Z}{\partial \lambda^{2}}= & -1, \quad \forall j=1,2, \ldots, m, \\
\frac{\partial^{2} Z}{\partial \mu^{2}}= & -1 \quad \forall j \quad
\end{aligned}
$$

$$
\frac{\partial^{2} Z}{\partial s^{2}{ }_{j}}=0 \quad \forall j=1,2, \ldots, m .
$$

For equation $m+1$, we have:

$$
\begin{aligned}
& \frac{\partial^{2} Z}{\partial \theta_{j}{ }^{2}}=-1 \quad \forall j=1,2, \ldots, m, \\
& \frac{\partial^{2} Z}{\partial \lambda^{2}}=0, \\
& \frac{\partial^{2} Z}{\partial \mu^{2}{ }_{j}}=0 \quad \forall j=1,2, \ldots, m, \\
& \frac{\partial^{2} Z}{\partial s^{2}{ }_{j}}=0 \quad \forall j=1,2, \ldots, m .
\end{aligned}
$$

For equations $m+2$ to $2 m+1$, we have:

$$
\begin{aligned}
& \frac{\partial^{2} Z}{\partial \theta_{j}{ }^{2}}=-1 \quad \forall j=1,2, \ldots, m, \\
& \frac{\partial^{2} Z}{\partial \lambda^{2}}=0, \\
& \frac{\partial^{2} Z}{\partial \mu^{2}{ }_{j}}=0 \quad \forall j=1,2, \ldots, m, \\
& \frac{\partial^{2} Z}{\partial s^{2}{ }_{j}}=2 s_{j} I \quad \forall j=1,2, \ldots, m .
\end{aligned}
$$

Finally, the gradient for equations $2 m+2$ to $3 m+1$ is defined as follows:

$$
\begin{aligned}
& \frac{\partial^{2} Z}{\partial \theta_{j}{ }^{2}}=0 \quad \forall j=1,2, \ldots, m, \\
& \frac{\partial^{2} Z}{\partial \lambda^{2}}=0, \\
& \frac{\partial^{2} Z}{\partial \mu^{2}{ }_{j}}=2 s_{j} I \quad \forall j=1,2, \ldots, m, \\
& \frac{\partial^{2} Z}{\partial s^{2}{ }_{j}}=2 \mu_{j} I \quad \forall j=1,2, \ldots, m .
\end{aligned}
$$

Therefore, the Jacobian matrix can be defined as follow:

$$
\left[\begin{array}{cccc}
\frac{f_{j}{ }^{2}}{\theta_{j}{ }^{3}} \xi\left(\frac{f_{j}}{\theta_{j}}\right) I_{m \times m} & -1_{1 \times m} & -I_{m \times m} & 0_{m \times m} \\
-1_{1 \times m} & 0_{1 \times 1} & 0_{1 \times m} & 0_{1 \times m} \\
-I_{m \times m} & 0_{m \times 1} & 0_{m \times m} & 2 s_{j} I_{m \times m} \\
0_{m \times m} & 0_{m \times 1} & 2 s_{j} I_{m \times m} & 2 \mu_{j} I_{m \times m}
\end{array}\right] \text { (39) }
$$

To define an appropriate robust estimator, we use Ruckstuhl and Welsh's [42] function $\rho(x)$ defined as follows:

$$
\rho(x)= \begin{cases}\left(\log \left(c_{1}+1\right)\right) x-c_{1}, & \text { if } x<c_{1} \\ x \log (x), & \text { if } c_{1} \leq x \leq c_{2} \\ \left(\log \left(c_{2}+1\right)\right) x-c_{2}, & \text { if } x>c_{2}\end{cases}
$$




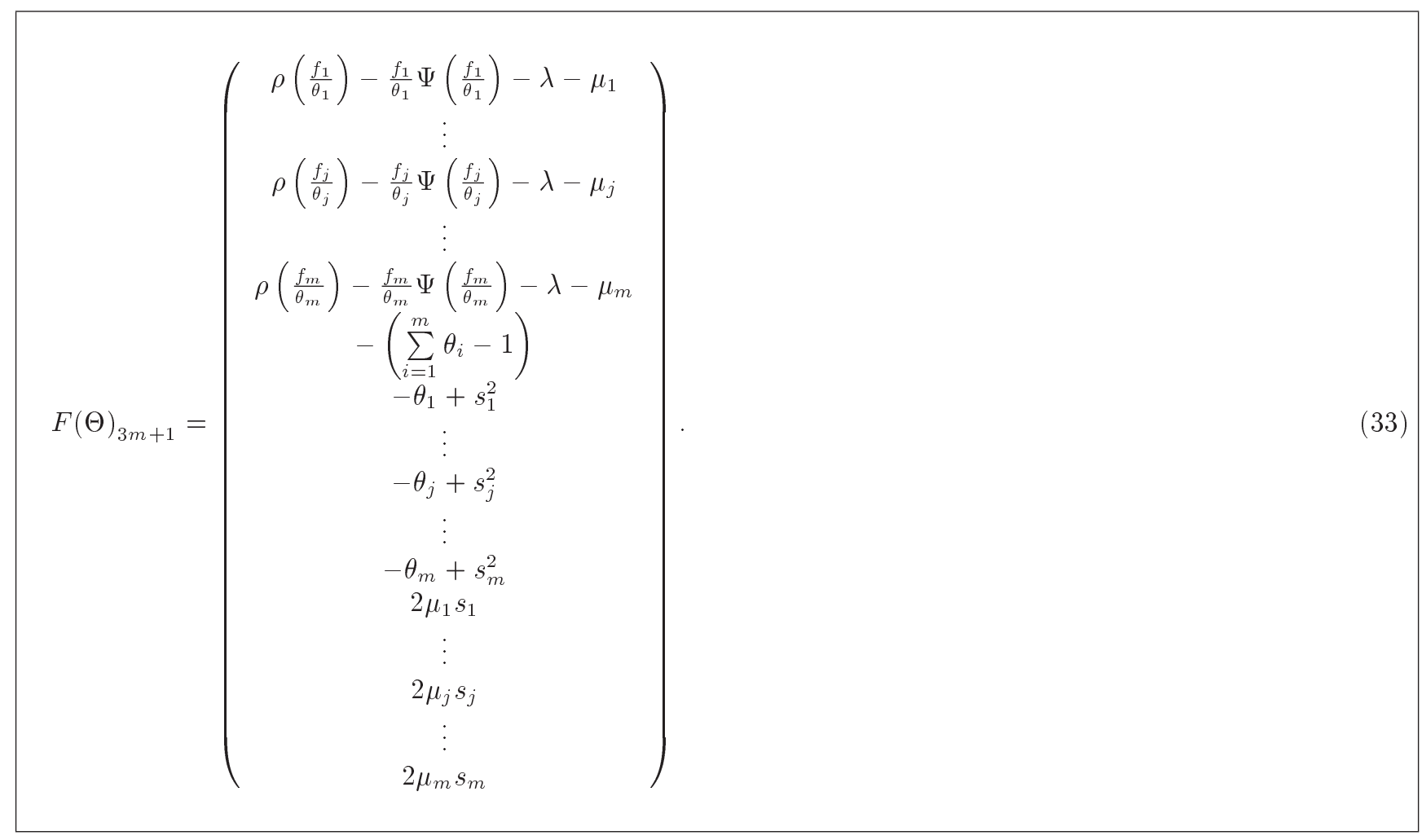

Box I

Table 3. Results of the simulations for different values of $c_{1}$ and $c_{2}$.

\begin{tabular}{cccccccccccc}
\hline $\boldsymbol{c}_{\boldsymbol{1}}$ & $\boldsymbol{c}_{\boldsymbol{2}}$ & Bias & $\boldsymbol{c}_{\boldsymbol{1}}$ & $\boldsymbol{c}_{\boldsymbol{2}}$ & Bias & $\boldsymbol{c}_{\boldsymbol{1}}$ & $\boldsymbol{c}_{\boldsymbol{2}}$ & Bias & $\boldsymbol{c}_{\boldsymbol{1}}$ & $\boldsymbol{c}_{\boldsymbol{2}}$ & Bias \\
\hline 0 & 0.8 & 0.35 & 0 & 1.2 & 0.40 & 0 & 1.6 & 0.27 & 0 & 1.8 & 0.27 \\
0.2 & 0.8 & 0.34 & 0.2 & 1.2 & 0.37 & 0.2 & 1.6 & 0.29 & 0.2 & 1.8 & 0.31 \\
0.4 & 0.8 & 0.36 & 0.4 & 1.2 & 0.36 & 0.4 & 1.6 & 0.3 & 0.4 & 1.8 & 0.3 \\
0 & 1 & 0.29 & 0 & 1.4 & 0.29 & $\mathbf{0}$ & $\mathbf{1 . 7}$ & $\mathbf{0 . 2 5}$ & 0 & 2 & 0.34 \\
0.2 & 1 & 0.3 & 0.2 & 1.4 & 0.33 & 0.2 & 1.7 & 0.28 & 0.2 & 2 & 0.35 \\
0.4 & 1 & 0.31 & 0.4 & 1.4 & 0.27 & 0.4 & 1.7 & 0.29 & 0.4 & 2 & 0.38 \\
\hline
\end{tabular}

In Eq. (40), $c_{1}$ and $c_{2}$ are defined in a way that obtained estimators have the highest robustness. Table 3 shows the results of the simulations for different values $c_{1}$ and $c_{2}$. The criterion used in this section is the asymptotic bias of estimation. This criterion is defined as the deviation between the values of parameters, estimated from the estimates.

The results show that $c_{1}=0$ and $c_{2}=1.7$ lead to appropriate results for the defined robust estimator.

\section{Results}

The results presented in this section are obtained based on the data collected from Shahid Madani hospital as a general surgery hospital, located in Karaj, Iran . The surgery divisions consist of 46 surgeons and 10 surgical specialties. The hospital is affiliated to Alborz University of Medical Sciences and located in an area about 8,000 square meters, with 195 beds.
Shahid Madani is referred to as a reference emergency hospital in Alborz province. In addition, it is the only burn care center in Alborz. This hospital consists of 2 ICU, 30 beds, 7 wards, and 165 beds in total. The burned patients' ward consists of 14 beds and is equipped with 3 intensive care beds. Note that, according to the OR facilities, there are some restrictions using OR for specific surgeries. Likewise, there are some surgical specialties with specific procedures that can only be executed in some special OR. Table 4 presents wards' capacity and combination of patients in the wards. In addition, it shows the OR corresponding to each surgical specialty.

To obtain the data required for this study, the information related to 19846 patients was registered for a period of 16 months in the course of March 20, 2014 to July 21, 2015 from Shahid Madani HIS. After omitting missed queries, the remaining records of 19242 patients are used in the study. According to the developed MSS 
Table 4. Wards capacity and combination of patients in each ward.

\begin{tabular}{|c|c|c|c|c|c|c|c|c|c|c|c|}
\hline \multirow{2}{*}{ Wards } & \multicolumn{10}{|c|}{ Surgical specialty } & \multirow{2}{*}{$\begin{array}{l}\text { Capacity } \\
\text { (number } \\
\text { of Beds) }\end{array}$} \\
\hline & CNS & ENT & Orology & Orthopedic & Eye & Hand & Burn & Vascular & General & Maxillofacial & \\
\hline Orkideh & $\mathrm{F}^{\mathrm{a}}$ & $\mathrm{F}$ & $\mathrm{F}$ & F & $\mathrm{F}$ & F & & F & $\mathrm{F}$ & $\mathrm{F}$ & 30 \\
\hline Ofogh & & & M & & & M & & M & & M & 20 \\
\hline Chakavak & $\mathrm{M}^{\mathrm{b}}$ & & & & & & & & & & 18 \\
\hline Shafagh & & & & M & & & & & & & 30 \\
\hline Ghasedak & $\mathrm{P}^{\mathrm{c}}$ & $\mathrm{M}, \mathrm{P}$ & $\mathrm{P}$ & $\mathrm{P}$ & $\mathrm{P}$ & $\mathrm{P}$ & & $\mathrm{P}$ & $\mathrm{P}$ & $\mathrm{P}$ & 18 \\
\hline Omid & & & & & & & $\mathrm{M}, \mathrm{F}, \mathrm{P}$ & & & & 14 \\
\hline Taranom & & & & & & & & & $\mathrm{M}$ & & 25 \\
\hline Negah & & & & & M & & & & & & 10 \\
\hline ICU 1 & $\mathrm{M}, \mathrm{F}, \mathrm{P}$ & $\mathrm{M}, \mathrm{F}, \mathrm{P}$ & $\mathrm{M}, \mathrm{F}, \mathrm{P}$ & $\mathrm{M}, \mathrm{F}, \mathrm{P}$ & $\mathrm{M}, \mathrm{F}, \mathrm{P}$ & $\mathrm{M}, \mathrm{F}, \mathrm{P}$ & & $\mathrm{M}, \mathrm{F}, \mathrm{P}$ & $\mathrm{M}, \mathrm{F}, \mathrm{P}$ & $\mathrm{M}, \mathrm{F}, \mathrm{P}$ & 27 \\
\hline ICU 2 & & & & & & & $\mathrm{M}, \mathrm{F}, \mathrm{P}$ & & & & 3 \\
\hline $\begin{array}{l}\text { OR related } \\
\text { to surgical } \\
\text { specialty }\end{array}$ & 1,3 & 8 & $1,2,3,4,5,6,7$ & $1,2,3,4$ & 9,10 & 7 & 8 & $1,2,3,4,5,6$ & $1,2,3,4,5,6$ & 8 & \\
\hline
\end{tabular}

Table 5. Model's parameters and estimation ways.

\begin{tabular}{|c|c|}
\hline Parameter & Description \\
\hline $\mathrm{Cap}_{\mathrm{i}}$ & The OR time allocated to surgical specialty $i$ in the CMP \\
\hline$O_{b r d}$ & $\begin{array}{l}\text { Opening hours of } \mathrm{OR} r \text { for elective surgeries in block } b \text { of day } d, O_{b r d} \text {, are derived from the empirical data. } \\
\text { This hours is calculated according to emergency demand for this block }\end{array}$ \\
\hline$D_{i}$ & Demand of elective patient's group $i$ in the week, $D_{i}$, is equal to the sum of the last year demand/52 \\
\hline$R_{\text {ir }}$ & This parameter is identified according to the interview with OR administrator \\
\hline$\alpha_{i}$ & $\begin{array}{l}\text { Maximum decrease rate of surgical specialty } i \text { capacity compared with the last year capacity, } \alpha_{i}, \\
\text { is derived according to hospital policy and is obtained according to the interview with hospital manager }\end{array}$ \\
\hline$w_{c}$ & Ward $c$ beds capacity, $w_{c}$, is achieved by the hospital documents \\
\hline$K_{i g c}$ & This parameter is identified according to hospital documents and interview with hospital matron \\
\hline$s t w_{i}$ & $\begin{array}{l}\text { Average LOS of surgical specialty } i \text { patients in the ward, } s t w_{i} \text {, is calculated using data } \\
\text { derived from empirical data of the HIS system }\end{array}$ \\
\hline$s t I_{i}$ & $\begin{array}{l}\text { Average LOS of surgical specialty } i \text { patients in the ICU, st } I_{i} \text {, is calculated using data } \\
\text { derived from empirical data of the HIS system }\end{array}$ \\
\hline$T_{i}$ & $\begin{array}{l}\text { Average surgery time duration of surgical specialty } i, T_{i} \text {, is calculated using data } \\
\text { derived from empirical data of the HIS }\end{array}$ \\
\hline$P N_{i}$ & $\begin{array}{l}\text { "Assigned priority" of surgical specialty } i, P N_{i} \text {, is calculated using TOPSIS } \\
\text { technique as described in Section } 3.2\end{array}$ \\
\hline
\end{tabular}

model, the list of parameters and the way to estimate them are summarized in Table 5.

Since the data used in this study are real data, the existence of contamination in the collected data is unavoidable. Therefore, E robust estimator is used and developed in Section 4.2 to estimate the model' parameters such that they are not sensitive to outlier data.

It is assumed that the opening hour of OR is
8 hours a day and they are open 5 days a week. The minimum block time required for each surgical specialty is calculated according to the maximum rate of decrease in the capacity of surgical specialty $i$ compared with that of the last year capacity. This parameter is defined based on the hospital policy and is identified by hospital managers. Defined planning horizon is a week, and the maximum OR block time allocated to each surgical specialty is less than its 
demand. The "assigned priority" of surgical specialties is calculated using TOPSIS technique, as described in Section 3.2.

\subsection{Application of TOPSIS technique to calculate "assigned priority"}

As discussed before, the data used in the modeling of the problem were obtained from Shahid Madani HIS. With respect to hospital policy, three criteria are taken into consideration to calculate "assigned priority" for each surgical specialty, as described in Section 3.2. In addition, TOPSIS method is applied to calculate values of these parameters and rank the surgical specialties' priorities based on these values. The first step in TOPSIS calculation is to create the evaluation matrix. Table 6 shows the evaluation matrix. Then, the decision matrix created in the first step is normalized using Eq. (B.1). In the next step, TOPSIS is applied to multiply normalized matrix by the weight vectors of the criteria using Eq. (B.2). The weight of each criterion is calculated based on the relative importance of each criterion related to the other criteria. As shown in Table 7 , priority weights of criteria are obtained through an interview with the hospital management team and the medical staff.

In order to determine the shortest distance from PIS and the farthest distance from the NIS, Eqs. (B.5) and (B.6) are applied, respectively. Eq. (B.1) makes it

Table 6. Values of the basic criteria of the surgical specialties.

\begin{tabular}{cccc}
\hline $\begin{array}{c}\text { Surgical } \\
\text { specialty }\end{array}$ & $\begin{array}{c}\text { Annual } \\
\text { elective } \\
\text { demand }\end{array}$ & $\begin{array}{c}\text { Number of } \\
\text { covering } \\
\text { hospital }\end{array}$ & $\begin{array}{c}\text { Rate of } \\
\text { emergency } \\
\text { surgery }\end{array}$ \\
\hline CNS & 400 & 5 & 0.0306 \\
ENT & 271 & 5 & 0.0089 \\
Orology & 353 & 7 & 0.0077 \\
Orthopedic & 3398 & 7 & 0.6211 \\
Eye & 813 & 6 & 0.0032 \\
Hand & 748 & 1 & 0.0659 \\
Burn & 114 & 0 & 0.0023 \\
Vascular & 104 & 3 & 0.0187 \\
General & 885 & 9 & 0.2387 \\
Maxillofacial & 104 & 0 & 0.0027 \\
\hline
\end{tabular}

Table 8. PIS, NIS, $s_{i \omega}$ and the rank of surgical specialty.

\begin{tabular}{ccccc}
\hline $\begin{array}{c}\text { Surgical } \\
\text { specialty }\end{array}$ & $\boldsymbol{d}_{\boldsymbol{i} \boldsymbol{\omega}}$ & $\boldsymbol{d}_{\boldsymbol{i b}}$ & $\boldsymbol{s}_{\boldsymbol{i} \boldsymbol{\omega}}$ & Rank \\
\hline CNS & 0.441753882 & 0.078834021 & 0.1514 & 8 \\
ENT & 0.456549143 & 0.073932683 & 0.1394 & 9 \\
Orology & 0.458020204 & 0.044295122 & 0.0882 & 10 \\
Orthopedic & 0.125368417 & 0.466770282 & 0.7883 & 1 \\
Eye & 0.408260449 & 0.094291543 & 0.1876 & 7 \\
Hand & 0.396121394 & 0.159356675 & 0.2869 & 3 \\
Burn & 0.463586792 & 0.161199278 & 0.2580 & 4 \\
Vascular & 0.458515719 & 0.107948676 & 0.1906 & 6 \\
General & 0.28357587 & 0.23208683 & 0.4501 & 2 \\
Maxillofacial & 0.465393872 & 0.161187965 & 0.2572 & 5 \\
\hline
\end{tabular}

possible to obtain the closeness coefficient $\left(s_{i \omega}\right)$ for each alternative, i.e., surgical specialty. Table 8 shows the value of parameters corresponding to PIS, NIS, $s_{i \omega}$, and the ranking of the surgical specialties, in which we can see that orthopedic specialty holds the highest priority. Note that $s_{i \omega}$ can be used as a surrogate for $P N_{i}$.

\subsection{Experimental results and sensitivity analysis}

Table 9 shows the values of the estimated parameters of the model. In this table, average duration of OT and LOS in the wards and ICU is calculated using E robust estimator, while $P N_{i}$ is derived from Table 8.

Table 9. Values of the required estimated model parameters.

\begin{tabular}{cccccccc}
\hline $\begin{array}{c}\text { Surgical } \\
\text { specialty }\end{array}$ & $\boldsymbol{C a p}_{\boldsymbol{i}}$ & $\boldsymbol{D Y}_{\boldsymbol{i}}$ & $\boldsymbol{\alpha}_{\boldsymbol{i}}$ & $\boldsymbol{s t w}_{\boldsymbol{i}}$ & $\boldsymbol{s t I}_{\boldsymbol{i}}$ & $\boldsymbol{T}_{\boldsymbol{i}}$ & $\boldsymbol{P N}_{\boldsymbol{i}}$ \\
\hline CNS & 58965 & 400 & 0.3 & 4.25 & 2.73 & 184 & 0.1514 \\
ENT & 15871 & 271 & 0.3 & 1.71 & 1.94 & 73 & 0.1394 \\
Orology & 27945 & 353 & 0.3 & 2.48 & 0.20 & 95 & 0.0882 \\
Orthopedic & 244634 & 3398 & 0.3 & 3.28 & 0.20 & 115 & 0.7883 \\
Eye & 50134 & 813 & 0.3 & 0.78 & 0.01 & 77 & 0.1876 \\
Hand & 71418 & 748 & 0.3 & 2.99 & 0.16 & 115 & 0.2869 \\
Burn & 9749 & 114 & 0.3 & 8.85 & 0.13 & 96 & 0.2580 \\
Vascular & 3561 & 104 & 0.3 & 4.23 & 1.93 & 78 & 0.1906 \\
General & 72565 & 885 & 0.3 & 3.24 & 0.34 & 105 & 0.4501 \\
Maxillofacial & 7451 & 104 & 0.3 & 3.41 & 0.23 & 101 & 0.2572 \\
\hline
\end{tabular}

Table 7. Weight vectors of the criteria.

\begin{tabular}{ccccc}
\hline & $\begin{array}{c}\text { Elective } \\
\text { demand }\end{array}$ & $\begin{array}{c}\text { Number of } \\
\text { covering } \\
\text { hospital }\end{array}$ & $\begin{array}{c}\text { Emergency } \\
\text { surgery } \\
\text { rate }\end{array}$ & $\boldsymbol{W}_{\boldsymbol{i}}$ \\
\hline Elective demand & 1 & 1.5 & 3.00 & 0.516 \\
Number of covering hospital & 0.67 & 1 & 1.50 & 0.297 \\
Emergency surgery rate & 0.33 & 0.67 & 1 & 0.188 \\
\hline
\end{tabular}


Table 10. Available time of OR.

\begin{tabular}{cccc}
\hline OR & Available time & OR & Available time \\
\hline 1 & 83667 & 6 & 121199 \\
2 & 89600 & 7 & 105909 \\
3 & 83667 & 8 & 121855 \\
4 & 89600 & 9 & 124491 \\
5 & 121199 & 10 & 124491 \\
\hline
\end{tabular}

Table 11. Ward available time.

\begin{tabular}{cccc}
\hline Ward & Available time & Ward & Available time \\
\hline Orkideh & 7717 & Omid & 4951 \\
Ofogh & 5863 & Taranom & 7862 \\
Chakavak & 6009 & Negah & 3639 \\
Shafagh & 3922 & ICU 1 & 8194 \\
Ghasedak & 4728 & ICU 2 & 1092 \\
\hline
\end{tabular}

Appropriate wards and OR for different surgical specialties are shown in Table 4, while available capacities of OR, wards, and ICU are shown in Tables 10 and 11, respectively.

In order to find the optimal MSS, an ILP model based on lexicographic goal programming approach is solved as a series of ILP using GAMS software and estimated parameters derived from the developed robust estimator and TOPSIS. In this study, the closeness between assigned time to surgical specialties and the time assigned to them resulting from CMP is the first priority, while the second priority is to minimize the sum of the spare capacity assigned to the surgical specialties in the MSS. The main results of the constructed MSS are presented in Table 12.

The results indicate that the proposed model obtains a better solution, i.e., $13.9 \%$ higher than that of the current solution put into practice by the hospital in terms of total sum of assigned priority of operated patients. In addition, solving the MSS according to Eq. (8) as the second objective function obtains less OR blocks spare time, i.e., $25.4 \%$ shorter than that of the solution using Eq. (7) as the first objective function. In addition, the results showed that for the majority of the cases, the optimum solution of MSS meets the respective time blocks assigned to each surgical specialty using CMPP. In the optimal solution, only $71 \%$ of total OR blocks is assigned to all surgical specialties, while, for the case of orthopedic surgical specialty, they can only cover $89.5 \%$ of their allocated capacity. The reason for facing idle capacity of some of the OR, while some surgical specialties have uncovered demand, may be attributed to the technical restriction on the OR facilities. In order to study the effect of the available time of OR blocks on the objective function, the proposed model has been solved in different scenarios in terms of available capacity of elective OR time. The results of the objective function improvement are presented in Figure 1.

As shown in Figure 1, increasing available elective OR block time can improve optimum solution up to $6.1 \%$. As mentioned earlier, in the optimum solution,

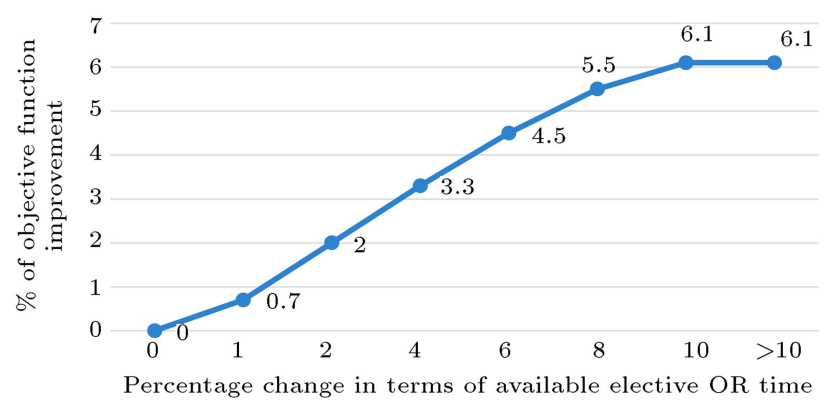

Figure 1. Objective function improvement against the change in the available elective OR time.

Table 12. Optimal MSS for Shahid Madani hospital.

\begin{tabular}{|c|c|c|c|c|c|c|c|c|c|c|}
\hline \multirow[b]{3}{*}{ OR } & \multicolumn{10}{|c|}{ Day } \\
\hline & \multicolumn{2}{|c|}{1} & \multicolumn{2}{|c|}{2} & \multicolumn{2}{|c|}{3} & \multicolumn{2}{|c|}{4} & \multicolumn{2}{|c|}{5} \\
\hline & Block 1 & Block 2 & Block 1 & Block 2 & Block 1 & Block 2 & Block 1 & Block 2 & Block 1 & Block 2 \\
\hline 1 & CNS & CNS & CNS & CNS & ORTO & CNS & ORTO & CNS & ORTO & ORTO \\
\hline 2 & ORTO & ORTO & ORTO & ORTO & ORTO & ORTO & ORTO & ORTO & ORTO & ORTO \\
\hline 3 & ORTO & ORTO & ORTO & ORTO & CNS & ORTO & CNS & ORTO & CNS & CNS \\
\hline 4 & ORTO & ORTO & ORTO & ORTO & ORTO & ORTO & ORTO & ORTO & ORTO & ORTO \\
\hline 5 & & GEN & GEN & ORO & GEN & VAS & GEN & GEN & ORO & \\
\hline 6 & & GEN & & & & & GEN & & VAS & \\
\hline 7 & ORO & HAND & HAND & HAND & HAND & HAND & HAND & HAND & HAND & \\
\hline 8 & & & & ENT & BURN & MAXI & BURN & & ENT & MAXI \\
\hline 9 & EYE & & EYE & & EYE & & EYE & & EYE & \\
\hline 10 & & & & & & & & & & \\
\hline
\end{tabular}


only $71 \%$ of total OR blocks are assigned to all surgical specialties, while, for some cases, they cannot cover all their allocated capacities. On the other hand, the optimal solution can improve as the available OR time increases. Furthermore, based on the results obtained, since there are some unassigned OR blocks in the optimum solution, this provides an opportunity for hospital managers to facilitate their idle OR in order to support the uncovered surgical specialties, if it is possible. The results of the sensitivity analysis also reveal that little changes to $\alpha_{i}$ have no considerable effect on the objective functions and wards, and ICU capacity is not a bottleneck in Shahid Madani hospital. Hence, the hospital managers shall focus on available OR elective capacity and their elective covering policy to improve the performance of MSS.

\section{Conclusion}

This paper studied the problem of MSS, considered as a tactical problem in OR planning and scheduling. For this purpose, an ILP model was developed to find the optimum MSS. In order to make the problem as real as possible, the constraints and the parameters' values were defined based on the data collected from Shahid Madani hospital. Two objective functions were considered in the MSS. An optimal MSS shall support the results of CMPP to the greatest extent possible. In addition, there were some sub-goals in the MSS problem, which should be optimized. Therefore, a lexicographic goal programming approach was developed to consider these criteria. Relative importance of elective operations for each surgical specialty was considered as one of the most important parameters considered in MSS, which was calculated using TOPSIS technique. The values of the parameters of the model were estimated using the data collected from Shahid Madani HIS. In order to overcome contaminations of the data and down weighting the outlier data, a robust estimator was applied to estimate the values of the model's parameters. After estimating the value of the parameters, the developed ILP model was solved using GAMS software. The results revealed that, compared with the current MSS, the proposed model results in an increase in total sum of "assigned priority" of operated patients by $13.9 \%$. In addition, a sensitivity analysis was conducted to study the effect of the values of the parameters on the total sum of "assigned priority" of operated patients. The results indicated that increasing available elective OR blocks time could improve this value by $6.1 \%$, while changes to and ICU and ward beds capacity did not have considerable effect on the MSS. For further study, it is proposed to study the problem in an uncertain environment in terms of either OT or LOS in the wards and ICU. In addition, it is proposed to study balancing hospital resources based on the best solution obtained for the CMPP.

\section{Acknowledgements}

The authors thank Shahid Madani hospital managers and staff for their supports in providing the data required and valuable comments.

\section{References}

1. Hof, S., Fügener, A., Schoenfelder, J., and Brunner, J.O. "Case mix planning in hospitals: a review and future agenda", Health Care Management Science, 20(2), pp. 207-220 (2017).

2. Hartman, M., Martin, A.B., Benson, J., and Catlin, A. National Health Expenditure Accounts Team. "National health spending in 2011: overall growth remains low, but some payers and services show signs of acceleration", Health Affairs, 32(1), pp. 87-99 (2013).

3. Denton, B., Viapiano, J., and Vogl, A. "Optimization of surgery sequencing and scheduling decisions under uncertainty", Health Care Management Science, 10(1), pp. 13-24 (2007).

4. Healthcare Financial Management Association "Achieving operating room efficiency through process integration", Healthcare Financial Management: Journal of the Healthcare Financial Management Association, 57(3), suppl-1 (2003).

5. Yahia, Z., Eltawil, A.B., and Harraz, N.A. "The operating room case-mix problem under uncertainty and nurses capacity constraints", Health Care Management Science, pp. 1-12 (2015).

6. Patterson, P. "What makes a well-oiled scheduling system", OR Manager, 12(9), pp. 19-23 (1996).

7. Dexter, F., Traub, R.D., and Macario, A. "How to release allocated operating room time to increase efficiency: predicting which surgical service will have the most underutilized operating room time", Anesthesia \& Analgesia, 96(2), pp. 507-512 (2003).

8. Vacanti, C., Segal, S., Sikka, P., and Urman, R. (Eds.), Essential Clinical Anesthesia, Cambridge University Press (2011).

9. Roth, A.V. and Van Dierdonck, R. "Hospital resource planning: concepts, feasibility, and framework", Production and Operations Management, 4(1), pp. 2-29 (1995).

10. Vissers, J.M., Bertrand, J.W.M., and De Vries, G. "A framework for production control in health care organizations", Production Planning \& Control, 12(6), pp. 591-604 (2001).

11. Hans, E.W., Van Houdenhoven, M., and Hulshof, P.J. "A framework for healthcare planning and control", In Handbook of Healthcare System Scheduling, pp. 303320 , Springer US (2012). 
12. Beliën, J., and Demeulemeester, E. "Building cyclic master surgery schedules with leveled resulting bed occupancy", European Journal of Operational Research, 176(2), pp. 1185-1204 (2007).

13. Samudra, M., Van Riet, C., Demeulemeester, E., Cardoen, B., Vansteenkiste, N., and Rademakers, F.E. "Scheduling operating rooms: achievements, challenges and pitfalls", Journal of Scheduling, 19(5), pp. 493-525 (2016).

14. Beliën, J., Demeulemeester, E., and Cardoen, B. "A decision support system for cyclic master surgery scheduling with multiple objectives", Journal of Scheduling, 12(2), pp. 147-161 (2009).

15. Van Oostrum, J.M., Van Houdenhoven, M., Hurink, J.L., Hans, E.W., Wullink, G., and Kazemier, G. "A master surgical scheduling approach for cyclic scheduling in operating room departments", OR Spectrum, 30(2), pp. 355-374 (2008).

16. Vissers, J.M.H., Adan, I.J., and Bekkers, J.A. "Patient mix optimization in tactical cardiothoracic surgery planning: a case study", IMA Journal of Management Mathematics, 16(3), pp. 281-304 (2005).

17. Holte, M. and Mannino, C. "The implementor/adversarial algorithm for cyclic and robust scheduling problems in health-care", Department of Computer and System Sciences Antonio Ruberti Technical Reports, 3(3), 19 pages (2011).

18. Fügener, A., Hans, E.W., Kolisch, R., Kortbeek, N., and Vanberkel, P.T. "Master surgery scheduling with consideration of multiple downstream units", European Journal of Operational Research, 239(1), pp. 227-236 (2014).

19. Dexter, F., Ledolter, J., and Wachtel, R.E. "Tactical decision making for selective expansion of operating room resources incorporating financial criteria and uncertainty in subspecialties' future workloads", Anes thesia \& Analgesia, 100(5), pp. 1425-1432 (2005).

20. Kharraja, S., Albert, P., and Chaabane, S. "Block scheduling: Toward a master surgical schedule", In Service Systems and Service Management, 2006 International Conference on, 1, pp. 429-435, IEEE (Oct. 2006).

21. Agnetis, A., Coppi, A., Corsini, M., Dellino, G., Meloni, C., and Pranzo, M. "Long term evaluation of operating theater planning policies", Operations Research for Health Care, 1(4), pp. 95-104 (2012).

22. Cappanera, P., Visintin, F., and Banditori, C. "Comparing resource balancing criteria in master surgical scheduling: A combined optimisation-simulation approach", International Journal of Production Economics, 158, pp. 179-196 (2014).

23. Banditori, C., Cappanera, P., and Visintin, F. "A combined optimization-simulation approach to the master surgical scheduling problem", IMA Journal of Management Mathematics, dps033, 24(2), pp. 155-187 (2013).
24. Cappanera, P., Visintin, F., and Banditori, C. "A goalprogramming approach to the master surgical scheduling problem", In Health Care Systems Engineering for Scientists and Practitioners, pp. 155-166, Springer International Publishing (2016).

25. Cappanera, P., Visintin, F., and Banditori, C. "Addressing conflicting stakeholders' priorities in surgical scheduling by goal programming", Flexible Services and Manufacturing Journal, 30(1-2), pp. 252-271 (2018).

26. Holte, M. and Mannino, C. "The implementor/adversary algorithm for the cyclic and robust scheduling problem in health-care", European Journal of Operational Research, 226(3), pp. 551-559 (2013).

27. Visintin, F., Cappanera, P., and Banditori, C. "Evaluating the impact of flexible practices on the master surgical scheduling process: an empirical analysis", Flexible Services and Manufacturing Journal, 28(1-2), pp. 182-205 (2016).

28. Rowse, E., Lewis, R., Harper, P., and Thompson, J. "Set partitioning methods for scheduling: an application to operating theatres", Simpòsio Brasileiro de Pesquisa Operacional (2014).

29. Fügener, A. "An integrated strategic and tactical master surgery scheduling approach with stochastic resource demand", Journal of Business Logistics, 36(4), pp. 374-387 (2015).

30. Van Oostrum, J.M., Bredenhoff, E., and Hans, E.W. "Suitability and managerial implications of a master surgical scheduling approach", Annals of Operations Research, 178(1), pp. 91-104 (2010).

31. Visintin, F., Cappanera, P., Banditori, C., and Danese, P. "Development and implementation of an operating room scheduling tool: an action research study", Production Planning \& Control, 28(9), pp. 758-775 (2017).

32. Mandic, K., Delibasic, B., Knezevic, S., and Benkovic, S. "Analysis of the financial parameters of Serbian banks through the application of the fuzzy AHP and TOPSIS methods", Economic Modelling, 43, pp. 30-37 (2014).

33. Hwang, C.L. and Yoon, K., Multiple Attribute Decision Making: Methods and Applications, New York: Springer-Verlag (1981).

34. Grubbs, F.E. "Procedures for detecting outlying observations in samples", Technometrics, 11(1), pp. 1-21 (1969).

35. Maddala, G.S. and Lahiri, K., Introduction to Econometrics, 2, New York: Macmillan (1992).

36. Huber, P.J., Robust Statistics, pp. 1248-1251, Springer, Berlin, Heidelberg (2011).

37. Freitas, A., Silva-Costa, T., Lopes, F., Garcia-Lema, I., Teixeira-Pinto, A., Brazdil, P., and Costa-Pereira, A. "Factors influencing hospital high length of stay outliers", BMC Health Services Research, 12(1), p. 1 (2012). 
38. Cots, F., Elvira, D., Castells, X., and Dalmau, E. "Medicare's DRG-weights in a European environment: the Spanish experience", Health Policy, 51(1), pp. 3147 (2000).

39. Pirson, M., Dramaix, M., Leclercq, P., and Jackson, T. "Analysis of cost outliers within APR-DRGs in a Belgian general hospital: two complementary approaches", Health Policy, 76(1), pp. 13-25 (2006).

40. Das, P., and Mandal, D., Statistical Outlier Detection in Large Multivariate Datasets, pp. 1-9. acsu.buffalo.edu

41. Zimek, A., Schubert, E., and Kriegel, H.P. "A survey on unsupervised outlier detection in high-dimensional numerical data", Statistical Analysis and Data Mining, 5(5), pp. 363-387 (2012).

42. Ruckstuhl, A.F. and Welsh, A.H. "Robust fitting of the binomial model", Annals of Statistics, 29(4), pp. 1117-1136 (2001).

\section{Appendix A}

To calculate the average requirements for the number of beds in ward $c$ on day $\tau$ for a procedure of patient sex specialty $g$ of surgical specialty $i$, if this operation is scheduled on day $d$, we have:

$$
\begin{aligned}
& \psi_{d^{\prime} \tau i g c}= \\
& \left\{\begin{array}{l}
\psi_{1 d^{\prime} \tau i g c} \quad \forall d^{\prime}, \tau, i, g, c=\{9,10\} \\
\psi_{2 d^{\prime} \tau i g c}-\psi_{1 d \tau i g c} \quad \forall d^{\prime}, \tau, i, g, c=\{1, \ldots, 8\}(\mathrm{A} .1)
\end{array}\right.
\end{aligned}
$$

in which $\psi_{1 d^{\prime} \tau i g c}$ and $\psi_{2 d^{\prime} \tau i g c}$ are defined in Box A.I.

To clarify the above-addressed expressions, a numerical example is provided. The example parameters are given in Table A.1.

To calculate $\psi_{1 d^{\prime} \text { i igc }}$, we have:
Table A.1. Example parameters for calculating $\psi_{1 d^{\prime} \tau i g c}$.

\begin{tabular}{ccccc}
\hline $\begin{array}{c}\text { LOS before } \\
\text { surgery }\end{array}$ & $\boldsymbol{D}$ & $\begin{array}{c}\text { LOS after } \\
\text { surgery }\end{array}$ & $\boldsymbol{\tau}$ & $\boldsymbol{\psi}_{\mathbf{1} \mathbf{d}^{\prime} \text { тigc }}$ \\
\hline 4 & 5 & 4 & 1 & $?$ \\
\hline
\end{tabular}

$$
\begin{aligned}
& d^{\prime}=d-\text { LOS before surgery }=1, \\
& L_{i g b}=4+4=8 .
\end{aligned}
$$

So:

$$
\begin{aligned}
\min & \{(1-1) \bmod 7,(1+8-2) \bmod 7\} \leq(1-1) \\
& \leq \max \{(1-1) \bmod 7,(1+8-2) \bmod 7\} \\
\Rightarrow 0 & \leq 0 \leq 0
\end{aligned}
$$

thus:

$$
\psi_{1 d^{\prime} \tau i g c}=\left\lceil\frac{L_{i b}}{T}\right\rceil=\left\lceil\frac{8}{7}\right\rceil=2,
$$

where, on Saturday, 2 beds are needed in ward $c$ (it is supposed that ward $c$ is appropriate for patient sex specialty $g$ of surgical specialty $i$ ) if a surgery in surgical specialty $i$ of patient sex specialty $g$ is required.

\section{Appendix B}

According to Hwang and Yoon [33], the TOPSIS process is defined as follows:

Step 1: An evaluation matrix, $\left(x_{i j}\right)_{m \times n}$ consisting of $m$ alternatives and $n$ criteria is created.

Step 2: Matrix $\left(x_{i j}\right)_{m \times n}$ is normalized to form matrix $R=\left(r_{i j}\right)_{m \times n}$ using Eq. (B.1):

$$
\psi_{1 d^{\prime} \tau i g c}=\left\{\begin{array}{cc}
\left\lceil\frac{L_{i g b}}{T}\right\rceil & \text { If } \quad \min \left\{\left(d^{\prime}-1\right) \bmod T,\left(d^{\prime}+L_{i g b}-2\right) \bmod T\right\} \leq \quad \forall d^{\prime}, \tau, i, g, c=\{9,10\} \\
\left\lfloor\frac{L_{i g b}}{T}\right\rfloor & \text { Otherwise }
\end{array}\right.
$$

$L_{i g b}=\mathrm{LOS}$ of ICU,

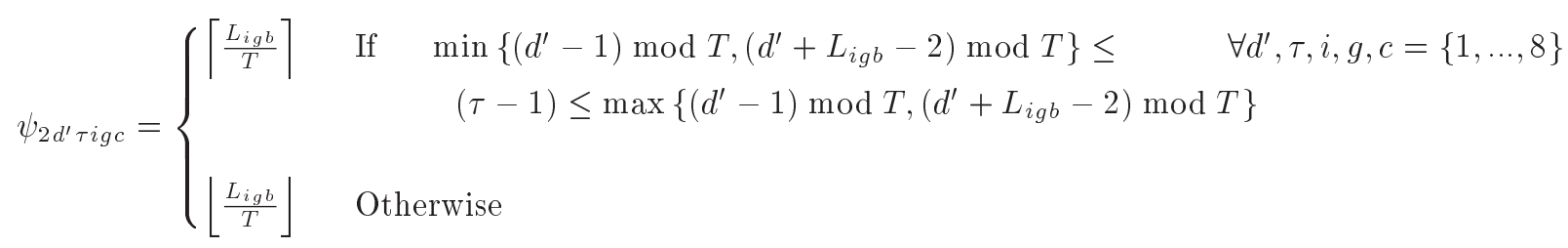

$L_{i g b}=$ Total LOS. 


$$
\begin{aligned}
& A_{\omega}=\left\{\left\langle\max \left(t_{i j} \mid i=1,2, \ldots, m\right)\right| j \in J_{-},\left\langle\min \left(t_{i j} \mid i=1,2, \ldots, m\right) \mid j \in J_{+}\right\rangle\right\}=\left\{t_{\omega j} \mid j=1,2, \ldots, n\right\} \\
& A_{b}=\left\{\left\langle\min \left(t_{i j} \mid i=1,2, \ldots, m\right)\right| j \in J_{-},\left\langle\max \left(t_{i j} \mid i=1,2, \ldots, m\right) \mid j \in J_{+}\right\rangle\right\}=\left\{t_{b j} \mid j=1,2, \ldots, n\right\}
\end{aligned}
$$

where:

$$
\begin{aligned}
& J_{+}=\{j=1,2, \ldots, n \mid j \text { associated with the criteria having a positive impact, and } \\
& J_{-}=\{j=1,2, \ldots, n \mid j \text { associated with the criteria having a negative impact. }
\end{aligned}
$$

\section{Box B.I}

$$
r_{i j}=\frac{x_{i j}}{\sqrt{\sum_{i=1}^{m} x_{i j}^{2}}}, \quad i=1,2, \ldots, m, \quad j=1,2, \ldots, n .
$$

Step 3: The weighted normalized decision matrix is calculated as follows:

$$
T=\left(t_{i j}\right)_{m \times n}=\left(\omega_{j} r_{i j}\right)_{m \times n}, \quad i=1,2, \ldots, m
$$

where $\omega_{j}=W_{j} / \sum_{j=1}^{n} W_{j}, j=1,2, \ldots, n$, so that $\sum_{j=1}^{n} \omega_{j}=1$, and $W_{j}$ is the original weight given to the indicator $v_{j}, j=1,2, \ldots, n$.

Step 4: The PIS $\left(A_{\omega}\right)$ and $\left(A_{b}\right)$ the NIS are determined as shown in Box B.I.

Step 5: The distance of each alternative from PIS and NIS is calculated using Eqs. (B.5) and (B.6)

$$
\begin{aligned}
& d_{i \omega}=\sqrt{\sum_{j=1}^{n}\left(t_{i j}-t_{\omega j}\right)^{2}, i=1,2, \ldots, m}, \\
& d_{i b}=\sqrt{\sum_{j=1}^{n}\left(t_{i j}-t_{b j}\right)^{2}, i=1,2, \ldots, m},
\end{aligned}
$$

where $d_{i \omega}$ and $d_{i b}$ are L2-norm distances from the target alternative $i$ to the worst and best conditions, respectively.

Step 6: The closeness coefficient for each alternative is calculated:

$$
s_{i \omega}=d_{i \omega} /\left(d_{i \omega}+d_{i b}\right), \quad 0 \leq s_{i \omega} \leq 1, \quad i=1,2, \ldots, m .
$$

Step 7: The alternatives are ranked according to $s_{i \omega}(i=1,2, \ldots, m)$.

\section{Biographies}

Rasoul Shafaei is an Associate Professor and the Head of MBA division in the Faculty of Industrial Engineering, at K.N. Toosi University of Technology. He has a PhD in Production Planning (1996) from UMIST, UK. He is the author and coauthor of more than 60 papers and books. His research interests include planning and scheduling on production and healthcare, supply chain design, and management and enterprise competitiveness.

Ashkan Mozdgir received a PhD degree at Industrial Engineering Department of K.N. Toosi University of Technology. He is the author and coauthor of more than 25 papers. His research interests include planning and scheduling on production and healthcare, line balancing and robust optimization. 